\title{
A comparative study of liquid, solid and hybrid adiabatic compressed air energy storage systems
}

\author{
Haobai Xue and Alexander White* \\ Department of Engineering, University of Cambridge, United Kingdom \\ *Corresponding author: ajw36@cam.ac.uk
}

\begin{abstract}
The increasing penetration of renewable energy sources into the power grid has prompted the development of many energy storage systems, amongst which Adiabatic Compressed Air Energy Storage (A-CAES) is deemed one of the more promising technologies. A-CAES systems can be categorized into solid A-CAES and liquid A-CAES, both of which have received extensive treatment in the literature. In this paper, thermodynamic and economic models are built for each of these systems and their sub-components, and the appropriate materials are selected for the corresponding Thermal Energy Storage (TES). A hybrid TES system is also considered, combining solid TES for low-pressure air with liquid TES for higher pressure. Results for this are compared with the other two systems. Parametric and optimisation studies have been carried out and suggest that the hybrid system has thermodynamic and economic advantages over the other two. The trade off between efficiency and cost and the factors affecting this trade off are also investigated.
\end{abstract}

\section{Introduction}

According to UK's target for the EU Renewable Energy Directive, more than 30\% of electricity will come from renewable energy sources by 2020 [1]. Much of this energy may be in the form of solar energy or wind (including off-shore wind) which are intermittent, difficult to predict and uncontrollable by nature [2]. These characteristics pose significant challenges for the large-scale integration of renewable generation into the power grid, for which production and consumption of electricity must exactly balance [3]. Load balancing issues are usually addressed by spinning reserve, such as peak-lopping gas turbines or coal fired power plant, but it is now accepted that storage is also likely to play a significant role, together with grid interconnection and demand-side management.

Energy storage systems convert surplus electricity into a storable form when supply exceeds demand, whilst during high demand, the stored energy is reconverted to electricity and then fed back to the power grid [4]. Adiabatic CAES is one of the various energy storage technologies being proposed [5]. During charge, air is compressed near-adiabatically and stored, typically in underground (but potentially also underwater) caverns, whilst the thermal energy (colloquially the "heat of compression") is stored separately. As discussed in [6], thermal storage may be achieved by cooling the air in heat exchangers which allow the energy to be transferred to liquid tanks. Alternatively, heat may be transferred directly to a solid storage material, for example in a packed bed. Research and development in this area has been very active in recent years. Bullough et al. [2] were the first to study and compare solid and liquid TES for A-CAES systems, proposing several suitable TES materials that cover temperatures from 50 to $650{ }^{\circ} \mathrm{C}$. RWE Power Ltd. proposed the ADELE project in Germany which is intended to operate at high temperature $\left(600{ }^{\circ} \mathrm{C}\right)$ and high pressure $(100 \mathrm{bar})$, with a targeted system efficiency of 70\% [7]. Barbour et al. [8] presented a thermodynamic analysis of a two-stage solid A-CAES system and suggested that solid A-CAES is superior to its liquid counterpart because this system has no costly thermal fluid requirements and enjoys higher system efficiency and energy density. These studies all propose high temperature TES systems, but there are also numerous concepts that operate in the range of 80 to $200{ }^{\circ} \mathrm{C}$. Low-temperature A-CAES (LTA-CAES) was advocated by Wolf et al. [9] who highlighted several advantages: fast cycling and wide-ranging part-load capability, and avoidance of various high-temperature challenges. These benefits come at the expense of lower efficiency, which is anticipated to be in the range 52 to $60 \%$. Grazzini and Milazzo [10] proposed a system in which the TES comprises pressurized water at $120^{\circ} \mathrm{C}$ combined with a high-pressure artificial air reservoir. The system efficiency is estimated at $72 \%$ which clearly competes with other energy storage technologies.

Many cycle analysis studies for A-CAES systems have been reported in the literature, including those of Luo et al. [6] for a liquid-based TES system, who concluded (not surprisingly) that efficiency is determined mainly by compression and expansion losses and heat exchanger effectiveness. Buffa et al. [11] proposed a system under the project "ENEL Ingegneria e Innovazione", with seven stages of compression and six stages of expansion. Due to the large number of stages, the TES temperature is low enough that ambient water can be used as the thermal fluid, but the system efficiency is estimated to be only $52 \%$. 


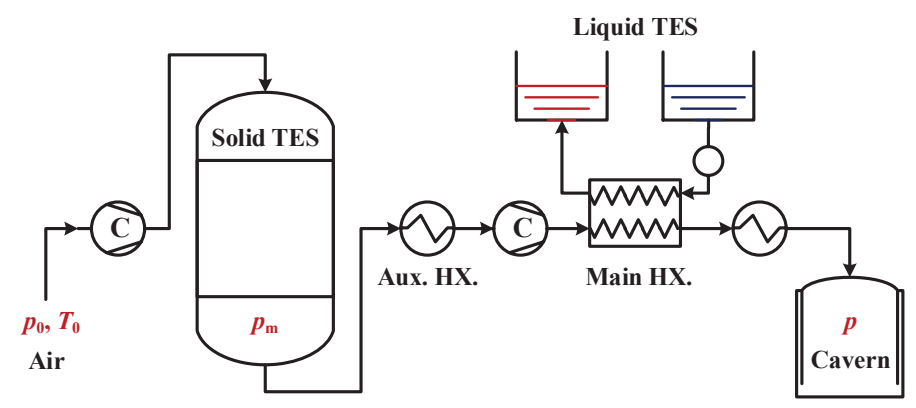

Figure 1: Schematic diagram of the hybrid A-CAES system

Despite these and many other studies of different A-CAES configurations, a comparative study of liquid and solid based systems from both thermodynamic and economic perspectives has so for been lacking. This forms the subject of the present paper, together with the investigation of a hybrid solid-liquid system aimed at achieving high efficiency whilst reducing capital cost. The motivation for hybrid A-CAES lies in the fact that the packed bed is generally more efficient and cheaper than heat exchangers at low pressure, but becomes exorbitantly expensive at high pressures.

\section{Systems description}

A general A-CAES configuration comprises $N$ stages of compression / expansion (with some form of TES between each stage) and an air-storage cavern or accumulator. The TES need not be the same for all stages: for example, for the system shown in Fig. 1, there is one stage of solid TES and two stages of liquid TES. This system is referred to as the hybrid A-CAES in this paper. If there are $n$ solid TES and $N-n$ liquid TES stages in the hybrid A-CAES, then the pressure ratio for each solid stage is:

$$
\beta_{i}=\left(\frac{p_{\mathrm{m}}}{p_{0}}\right)^{\frac{1}{n}} \quad(i \leq n)
$$

and that for each liquid stage is:

$$
\beta_{i}=\left(\frac{p}{p_{\mathrm{m}}}\right)^{\frac{1}{N-n}} \quad(i>n)
$$

where $p_{0}, p_{\mathrm{m}}$ and $p$ refer to pressures in the atmosphere, after the last solid stage and in the cavern respectively (see Fig. 1). For a solid only system $p_{\mathrm{m}}=p$, whereas for a liquid only system $p_{\mathrm{m}}=p_{0}$. The heat transfer between the compressed air and the liquid media is achieved through the main heat exchangers, for which the heat transfer losses are inversely related to the size and cost of the device. This indirect contact separates the working fluid from the liquid media and thus enables the cost of liquid TES to be independent of the operating air pressure. For solid TES, on the other hand, it is easier to exploit direct-contact heat transfer between the air and solid media. For example, a packed-bed thermal reservoir can fulfil this function, and the heat transfer losses can be decreased by reducing the particle size, without increasing the capital cost simultaneously. However, direct-contact heat transfer requires the operating pressure of the solid TES to be the same as that of the air, thus the capital cost of solid TES (dominated by the pressure vessel) is more or less proportional to the operating pressure. However, solid TES benefits from a wider temperate range and as a result it is usually operated at higher temperature, typically $\sim 600{ }^{\circ} \mathrm{C}$. Liquid storage is generally operated at temperatures up to $\sim 300{ }^{\circ} \mathrm{C}$, depending on the storage fluid and storage pressure. It is assumed here that all like forms of storage (i.e., solid or liquid) have the same maximum allowable temperature and hence the pressure ratio is equally partitioned amongst each like stage (see Eqs. 1 \& 2).

Auxiliary heat exchangers are included in the cycle after each TES, as shown in Fig. 1, to further cool the air to ambient temperature $T_{0}$. This prevents the inlet temperature of the next stages becoming too high if the solid TES is small (such that thermal fronts emerge from their exit) or the liquid TES is inefficient. Since the waste heat is not recycled but simply dissipated in the auxiliary heat exchangers, a high water flow rate (hence a low heat capacity ratio $C_{r}$ ) is usually adopted to reduce the heat exchanger size and cost. The effectiveness of any heat exchanger with $C_{r}=0$ is given by $\varepsilon=1-\exp (-\mathrm{NTU})$ [12], so with with the 'number of thermal units' as low as $\mathrm{NTU}=2$ an effectiveness $\varepsilon$ of 0.86 is attained. This type of auxiliary heat exchange is used for each TES and its cost added into the total, as described in section 4 .

In the absence of pressure losses (as in many cycle analyses) the stage pressure during compression (charge) and expansion (discharge) are the same so that $\beta_{\mathrm{c}}=\beta_{\mathrm{e}}=\beta_{i}$. However, in order to study the impact of pressure 
losses (for example, those generated by heat exchangers and packed beds) in a simple and general manner, a pressure loss factor $f_{p}$ is applied to each stage. Thus the actual stage compression ratio becomes $\beta_{\mathrm{c}}=\beta_{i} /\left(1-f_{p}\right)$, whilst stage expansion ratio is $\beta_{\mathrm{e}}=\beta_{i}\left(1-f_{p}\right)$. In practice, the pressure loss factors are dominated by viscous effects in heat exchangers and packed beds, as described in section 3.

After $N$ stages of compression, the compressed air is finally stored in an air reservoir, as shown in Fig. 1. Although artificial caverns have been proposed by many researchers, the size needed for a large-scale CAES installation $(400-800 \mathrm{MWh})$ is in the range of 150,000 to $500,000 \mathrm{~m}^{3}$. Solution mining or the use of existing natural caverns are therefore the most feasible options. In the present study the nominal energy and power are set as $400 \mathrm{MWh}$ and $100 \mathrm{MW}$ respectively and the cavern volume is calculated from the energy distribution between the cavern and each TES. The cavern is assumed isochoric by nature and therefore the pressure varies within a range $p_{\min }$ to $p_{\max }$. The value of $p_{\max }$ is constrained by geological conditions (e.g., the depth of the cavern) whilst $p_{\min }$ is determined by the extent of discharge and the minimum pressure required to maintain the cavern's integrity. Storage density and round-trip efficiency will in general depend on both $p_{\max }$ and the ratio $p_{\min } / p_{\max }$.

The TES subsystems all include the following three components: storage material (i.e. liquid or solid), containment vessel (or tank) and an insulation layer. For solid TES, the commonly used packing materials are natural stones, ceramic and metal oxides, which are generally very cheap and have wide temperature range. Materials selection essentially becomes finding the substance with the largest volumetric heat capacity because cost tends to be dominated by the pressure vessel. On the basis of work reported in [13], magnetite $\left(\mathrm{Fe}_{3} \mathrm{O}_{4}\right)$ has been used as the solid storage medium for the analysis presented here, and the maximum temperature is set at $600{ }^{\circ} \mathrm{C}$. For liquid TES, mineral oil, molten salt and water are the most widely used thermal fluids. Their selection, however, is less straightforward due to the vast differences of cost, heat capacity and operating temperature range. A simple multi-objective optimization has therefore been carried out (see Section 6.3), from which mineral oil has been selected as the best option. The maximum allowable temperature is accordingly set at $340{ }^{\circ} \mathrm{C}[14,15]$.

\section{Thermodynamic modelling of components}

\subsection{Solid TES systems}

Solid TES is assumed to be provided by packed-bed thermal reservoirs. (Solid storage with indirect heat exchange has not been considered here.) Equations governing the behaviour of such reservoirs have been presented many times in the literature, e.g., [16-18]. The model used here is that described in Refs. [13, 18, 19] and is based on the well-established Schumann model. Although the numerical method employed takes account of additional phenomena (such as unsteady terms for the gas phase and temperature-dependent heat capacities) the propagation of thermal fronts within the packed bed is described to a good approximation by:

$$
\begin{aligned}
& \frac{\partial T_{\mathrm{g}}}{\partial z}=\frac{T_{\mathrm{s}}-T_{\mathrm{g}}}{l} \\
& \frac{\partial T_{\mathrm{s}}}{\partial t}=\frac{T_{\mathrm{g}}-T_{\mathrm{s}}}{\tau}
\end{aligned}
$$

where $l$ and $\tau$ are length and time scales as given in Ref. [18]. The pressure loss along the thermal reservoir is also considered and calculated from:

$$
\frac{\mathrm{d} p}{\mathrm{~d} z}=-\frac{S_{v}(1-\varepsilon) c_{f} G^{2}}{2 \varepsilon^{3} \rho_{\mathrm{g}}}
$$

where $S_{v}$ is the particle surface-to-volume ratio $\left(=6 / d_{p}\right.$ for spherical particles), $\varepsilon$ (here) is the void fraction, and $c_{f}$ is the friction coefficient, which is obtained from the Carman correlation given in Ref. [20].

Three design parameters are used here to model the performance of the thermal reservoir: the 'utilisation factor' $\Pi$, the particle equivalent diameter $d_{p}$ and the reservoir aspect ratio $L / D$. Note that the utilisation factor is defined by $\Pi=t_{\text {chg }} / t_{\text {nom }}$, i.e., it is the ratio between the actual and nominal charge times, this being approximately the ratio between the stored energy per cycle and the full-charge value.

\subsection{Liquid TES systems}

In liquid A-CAES, thermal fluid tanks are the counterparts of the packed-bed thermal reservoirs. The governing equations are essentially the mass and energy conservation equations. These are very similar to those of the cavern in Section 3.5 and are thus omitted to avoid redundancy. 


\subsection{Compressors and expanders}

These are assumed adiabatic and are modelled by means of a simple polytropic or 'infinitesimal stage' efficiency, defined by $\eta_{\mathrm{c}}=-v \mathrm{~d} p / \delta w$ for compression or $\eta_{\mathrm{e}}=-\delta w / v \mathrm{~d} p$ for expansion. This is deemed preferable to the use of isentropic efficiencies which yield anomalies when, for example, compression and expansion are divided into multiple stages. Compressor exit temperatures $T_{\text {out }}$ and specific work $w_{\mathrm{c}}$ are thus computed from

$$
\begin{gathered}
T_{\text {out }}=T_{\text {in }} \beta_{\mathrm{c}}^{\phi_{\mathrm{c}}} \\
w_{\mathrm{c}}=c_{p} T_{\text {in }}\left(\beta_{\mathrm{c}}^{\phi_{\mathrm{c}}}-1\right)
\end{gathered}
$$

where $c_{p}$ is the air's heat capacity, subscript 'in' denotes compressor inlet and $\phi_{\mathrm{c}}=(\gamma-1) /\left(\gamma \eta_{\mathrm{c}}\right)$ is the polytropic exponent. Equivalent expressions for expansion are obtained by replacing $\eta_{\mathrm{c}}$ with $\eta_{\mathrm{e}}^{-1}$.

\subsection{Heat exchangers}

For liquid TES heat is transferred between the working fluid and the thermal fluid via a heat exchanger. To minimise losses associated with irreversible heat transfer, a counter flow heat exchanger with $C_{r}=1$ (i.e., balanced flow) is employed and the well-established $\varepsilon-\mathrm{NTU}$ method is used for the simulation. The heat exchanger effectiveness $\varepsilon=\left|T_{\text {in }}-T_{\text {out }}\right| /\left(T_{\text {in,hot }}-T_{\text {in,cold }}\right)$ is then the only parameter needed to evaluate thermal performance and heat exchanger outlet temperatures are given by

$$
\left(\begin{array}{c}
T_{\text {out, a }} \\
T_{\text {out }, \mathrm{f}}
\end{array}\right)=\left(\begin{array}{cc}
1-\varepsilon & \varepsilon \\
\varepsilon & 1-\varepsilon
\end{array}\right)\left(\begin{array}{c}
T_{\text {in, a }} \\
T_{\text {in }, \mathrm{f}}
\end{array}\right)
$$

where the subscripts a and $\mathrm{f}$ denote air and (storage) fluid respectively. For a counter-flow heat exchanger with $C_{r}=1$ the effectiveness is related to the 'number of thermal units' $\left(\mathrm{NTU}=\mathrm{UA} / \mathrm{C}_{\min }\right.$ ) by (see [12]):

$$
\varepsilon=\frac{\mathrm{NTU}}{\mathrm{NTU}+1}
$$

Knowing the NTU enables an estimate of the heat exchanger cost and the pressure loss, the latter being determined from (see [21]):

$$
\Delta p=\frac{G^{2}}{\bar{\rho}} \frac{c_{f}}{\mathrm{St}} \mathrm{NTU}
$$

where $\bar{\rho}$ is the average density between inlet and outlet, and $c_{f} / \mathrm{St}$ is a constant and equal to $2 \mathrm{P}^{\frac{2}{3}}$ for turbulent flow (see [21]). The mass flow rate per unit area $G$ is set at $37 \mathrm{~kg} \mathrm{~m}^{-2} \mathrm{~s}^{-1}$ so that the corresponding Reynolds number is $\sim 6000$, which is above the turbulence threshold of 3000; the inner diameter of the heat exchanger tubes is set at $3.0 \mathrm{~mm}$, which is the smallest size available commercially from multiple sources [22].

\subsection{Cavern modelling}

The dyanmics of the cavern (or air receiver) must satisfy the conservation equations for mass and energy. For a constant volume (isochoric) cavern of volume $V$, these may be written:

$$
\begin{gathered}
\frac{\mathrm{d} m}{\mathrm{~d} t}=\dot{m}_{\mathrm{in}}-\dot{m}_{\text {out }} \\
\frac{\mathrm{d} T}{\mathrm{~d} t}=\frac{1}{m c_{v}}\left[\dot{Q}+\dot{m}_{\mathrm{in}} c_{p} T_{\mathrm{in}}-\dot{m}_{\text {out }} c_{p} T-\frac{\mathrm{d} m}{\mathrm{~d} t} c_{v} T\right]
\end{gathered}
$$

where $m$ and $T$ are the mass and temperature of the cavern air respectively. These equations are completed by equations of state which, for the present analysis, are based on perfect gas relations. The heat transfer rate to the cavern from the surroundings, $\dot{Q}$, is quantified by the dimesionless parameter

$$
\lambda=\frac{\dot{Q}}{\dot{m} c_{p}\left(T-T_{0}\right)}=\mathrm{St} \frac{A}{A_{\mathrm{c}}}
$$

where $A$ and $A_{\mathrm{c}}$ are the cavern surface area and cross-sectional inlet area respectively, and St is the Stanton number, $\mathrm{St}=U A_{c} /\left(\dot{m} c_{p}\right)$, with $U$ being the overall heat transfer coefficient. As the the coefficient $\lambda$ increases from 0 to $\infty$, the behaviour of the cavern changes from adiabatic to isothermal. Natural caverns lie somewhere in the intermediate range and a nominal value of $\lambda=10$ has been used for most calculations, but the effect of different values on cost and efficiency is explored in section 5.1. 


\section{Cost modelling of components}

The objective here is to provide a reasonable comparison between the initial capital costs of different designs. Cost equations for the major system components are therefore set out and justified in this section. Although efforts have been made to ensure that these are as accurate as possible, it should be noted that they are still subject to significant uncertainty and should be treated accordingly with caution. Furthermore, only costs that have a direct impact on the following parametric and optimisation studies are included. Other costs such as electrical and control costs, materials, labour, operating and indirect costs are not included.

\subsection{TES system costs}

The TES systems all consist of similar components and the capital cost can be estimated from the following relation proposed in Ref. [23]:

$$
Z_{\mathrm{TES}}=k_{\mathrm{fil}} V_{\mathrm{fil}}+k_{\mathrm{ins}} V_{\mathrm{ins}}+k_{\mathrm{PV}} p V
$$

where $k_{\text {fil }}$ and $k_{\text {ins }}$ are costs per unit volume of the filling (storage material) and insulation respectively, whilst $k_{\mathrm{PV}}$ is the cost of the pressure vessel (including material and fabrication) per bar per unit volume. The coefficients used in Eq. (14) are summarized in Table 1.

Determining the required thickness of insulation is based on the fractional energy loss per day, which can be estimated from the simple lumped-capacity heat transfer model [19]:

$$
\frac{\mathrm{d} E_{\mathrm{fil}}}{d t}=-\frac{E_{\mathrm{fil}}}{\tau_{\mathrm{ins}}}
$$

where $\tau_{\text {ins }}=\rho_{\text {fil }} c_{\text {fil }} /\left(U_{\text {ins }} S_{\mathrm{TES}}\right)$ is a heat leakage time constant, $S_{\mathrm{TES}}$ is the surface-to-volume ratio of the TES subsystem and $U_{\text {ins }}$ is the overall heat transfer coefficient. For instance, setting the fractional energy loss rate to $0.5 \%$ per day corresponds to a time constant $\tau_{\text {ins }}$ of 200 days, and for the nominal design $\left(S_{\text {TES }}=2 / D\right.$ including hemispherical ends and setting $L / D$ to 1$)$, the overall heat transfer coefficient $U_{\text {ins }}=\rho_{\text {fil }} c_{\text {fil }} D / 8 \tau_{\text {ins }} \approx 0.12 \mathrm{~W} /\left(\mathrm{m}^{2} \cdot \mathrm{K}\right)$. $U_{\text {ins }}$ is mainly determined by the thermal resistance $\lambda_{\text {ins }}$ and thickness $\delta_{\text {ins }}$ of the insulation layer, and therefore $\delta_{\text {ins }}$ can be estimated from the following cylindrical heat conduction equation:

$$
\delta_{\text {ins }}=R\left[\exp \left(\frac{2 \lambda_{\text {ins }}}{D U_{\text {ins }}}\right)-1\right]
$$

However, the lumped capacity model is only valid if the temperature is radially uniform within the storage media. This is a good assumption for liquid TES due to mixing, but for solid systems the Biot numbers are likely to be sufficient to cause significant radial non-uniformity that would invalidate the use of the 1-D Schumann-style model [19]. An additional constraint is thus placed on the temperature drop that would occur at the outer edge of the storage material, which effectively limits the Biot number and hence the maximum allowable overall heat transfer coefficient $U_{\text {ins. }}$. Details of how this is implemented are provided in Ref. [19].

\subsection{Compressor and expander costs}

The equations for estimating the capital cost of compressors and expanders are taken from the well-known CGAM problem, which was developed by a group of concerned specialists in the field of thermo-economics (C. Frangopoulos, G. Tsatsaronis, A. Valero, M. von Spakovsky, and co-workers) in the early 90s. This has been used as the standard test case for the comparison of different thermo-economic optimisation methods ever since [24]. The cost equations are adapted here to make them more compatible with the polytropic processes and the coefficients are adjusted to the data provided by Schainker [25] to account for inflation. Costs for both compressors and expanders are estimated from:

$$
Z_{\mathrm{c} / \mathrm{e}}=\sum_{i=1}^{N} \frac{C_{\mathrm{c} / \mathrm{e}} \dot{m} \ln \beta_{i}}{\eta_{\max }-\eta}
$$

where $\eta$ and $\dot{m}$ are the polytropic efficiency and the mass flowrate respectively $\left(\eta_{\mathrm{c}}\right.$ and $\dot{m}_{\text {chg }}$ for compressors, $\eta_{\mathrm{e}}$ and $\dot{m}_{\text {dis }}$ for expanders). $\eta_{\max }$ is set at 0.92 in accord with Refs. [24, 26, 27] and by comparison with data, as shown in Fig. 2. Eq. (17) encapsulates the increase in compressor / expander cost with mass flowrate $\dot{m}$, system pressure ratio $p / p_{0}$ and component efficiency $\eta$. It suggests that the total cost is independent of how the system pressure ratio is distributed between each stage. The coefficients used in Eq. (17) are based on centrifugal compressor and turbo-expanders [25] and are summarized in Table 1. As with heat exchangers, three different cases (nominal, 
Table 1: Constants used in the equations for the purchase cost of the components

\begin{tabular}{llll}
\hline Components & Nominal & Pessimistic & Optimistic \\
\hline Compressor & $C_{\mathrm{cn}}=670 \$ /(\mathrm{kg} / \mathrm{s})$ & $\left.C_{\mathrm{cp}}=871 \$ / \mathrm{kg} / \mathrm{s}\right)$ & $C_{\mathrm{co}}=469 \$ /(\mathrm{kg} / \mathrm{s})$ \\
Expander & $C_{\mathrm{en}}=1116 \$ /(\mathrm{kg} / \mathrm{s})$ & $C_{\mathrm{ep}}=1451 \$ /(\mathrm{kg} / \mathrm{s})$ & $C_{\mathrm{eo}}=781 \$ /(\mathrm{kg} / \mathrm{s})$ \\
Heat Exchanger & $C_{\mathrm{hn}}=38880 \$ /(\mathrm{kg} / \mathrm{s})^{0.6}$ & $C_{\mathrm{hp}}=50544 \$ /(\mathrm{kg} / \mathrm{s})^{0.6}$ & $C_{\mathrm{ho}}=27216 \$ /(\mathrm{kg} / \mathrm{s})^{0.6}$ \\
\hline Components & Constants & & \\
\hline Thermal Reservoir & $k_{P V}=250 \$ / \mathrm{bar} \cdot \mathrm{m}^{3}$ & $k_{\text {fil }}=200 \$ / \mathrm{m}^{3}$ & $k_{\text {ins }}=1500 \$ / \mathrm{m}^{3}$ \\
Thermal Fluid Tanks & $k_{\mathrm{hot}}=500 \$ / \mathrm{m}^{3}$ & $k_{\mathrm{cold}}=100 \$ / \mathrm{m}^{3}$ & \\
Cavern & $C_{\mathrm{well}}=41275 \$ / \mathrm{bar}$ & $C_{\text {mine }}=0.11 \$ / \mathrm{bar} \cdot \mathrm{m}^{3}$ & \\
\hline
\end{tabular}

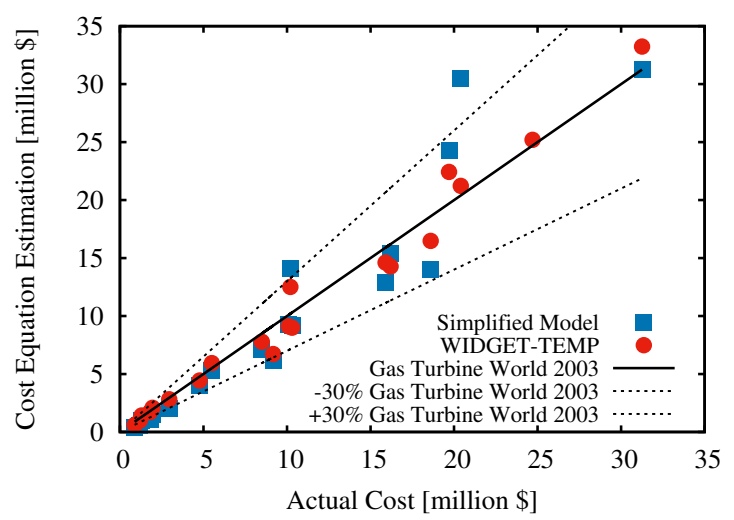

Figure 2: Validation of the compressor/expander cost equations

pessimistic and optimistic) are given to account for the uncertainty inherent in all cost modelling. The impact of cost equations on the final results will be discussed in section 6.4.

Compressor and expander costs estimated from the above simplified model are compared in Fig. 2 with actual costs and with costs estimated from the considerably more complex 'WIDGET-TEMP' model described in Ref. [28]. The solid line denotes estimated cost equal to actual cost, which is unlikely to be achieved by any model given fluctuations in actual cost. It is notable that the simplified model tends to underestimate costs in the low-power range and overestimate them at high power. This is because marginal costs tend to decrease with increasing power output, and this is not accounted for in the model. Nonetheless, estimates generally fall within $\pm 30 \%$ of actual values and Eq. (17) is much simpler than the 'WIDGET-TEMP' approach, which requires 22 input parameters.

\subsection{Heat exchanger costs}

Since the NTU is proportional to heat transfer area of the heat exchanger, it is also used in this study to estimate the capital cost through:

$$
Z_{\mathrm{HEX}}=\sum_{i=1}^{N-n} C_{\mathrm{hex}}\left(\dot{m} \cdot \mathrm{NTU}_{i}\right)^{0.6}
$$

This relation is also taken from the CGAM problem, adapted to the cost data provided by Schainker [25]. It indicates cost increasing with both flowrate and NTU because increasing either of these calls for larger heat transfer area. The index of 0.6 is based on the 'rule of the six-tenths' which can give an approximate cost within $\pm 20 \%$ [29]. The coefficients used in Eq. (18) are summarised in Table 1.

\subsection{Cavern costs}

The cost of a cavern depends largely on its source, type and geological condition. In the present work, only solution-mined caverns are considered due to their technical maturity, wide availability and relatively low capital cost. The overall cavern cost can be divided into the well cost and the solution-mining cost, both of which are proportional to the cavern depth (because deeper caverns call for more drilling and pumping). In addition, the well 
Table 2: Nominal, minimum and maximum values of the design variables for the parametric study

\begin{tabular}{ccccccccc}
\hline & $p_{\max }(\mathrm{bar})$ & $p_{\min } / p_{\max }$ & $\lambda$ & $\mathrm{NTU}$ & $\eta$ & $\Pi$ & $d_{p}(\mathrm{~mm})$ & $L / D$ \\
\hline Nominal & 120 & 0.60 & 10.00 & 9.00 & 0.85 & 0.80 & 15.0 & 1.00 \\
Minimum & 40 & 0.30 & 0.001 & 1.00 & 0.80 & 0.50 & 2.00 & 0.20 \\
Maximum & 200 & 0.90 & 1000 & 49.0 & 0.90 & 1.50 & 30.0 & 6.00 \\
\hline
\end{tabular}

cost is proportional to the diameter of the bore hole whilst the mining cost is proportional to the cavern volume $V$. Since the rated power of the three types of A-CAES considered here is close to that of the McIntosh plant, the size of the bore hole is considered as constant and not taken into account in the cost equation. The cavern depth, according to Ref. [30], is proportional to the maximum cavern pressure $p_{\max }$. The following cost relation is thus applied:

$$
Z_{\mathrm{cav}}=\left(C_{\mathrm{well}}+C_{\operatorname{mine}} V\right) p_{\max }
$$

where $C_{\text {well }}$ and $C_{\text {mine }}$ are coefficients corresponding to drilling and solution mining respectively, values of which (corrected for inflation) are inferred from the McIntosh CAES plant costs and are summarised in Table 1.

\section{Parametric Studies}

Before embarking on optimisation of the different systems, it is useful to first consider the effect of varying the various design parameters on both sytem cost and efficiency. The number of stages for solid, hybrid and liquid systems is set at two, three and four respectively, with each solid TES roughly equivalent to two liquid ones. This is a consequence of the higher maximum permissible temperature for solid systems. Other design variables and their ranges are summarised in Table 2. As each parameter is varied all others are held at their nominal values. The effect of these parameter variations on performance is evaluated in terms of efficiency $\chi=W_{\text {dis }} / W_{\text {chg }}$ and unit storage $\operatorname{cost} Z=Z_{\text {tot }} / W_{\text {dis }}$, where $W_{\text {chg }}$ and $W_{\text {dis }}$ are the work input and output, obtained by integrating power over the charge and discharge times respectively. The total cost $Z_{\text {tot }}$ is simply the sum of the various component costs, as described in section 4. Mechanical (friction) losses and electrical losses are not accounted for, so $\chi$ constitutes a "thermodynamic" round-trip efficiency. Likewise, the costs are limited to the "thermodynamic" components, as $Z_{\text {tot }}$ does not include motor and generator costs. However, as shown in Ref. [31], these are usually a simple function of rated power and will therefore remain constant across the different designs considered here.

\subsection{Effect of cavern parameters}

Figures $3 \mathrm{a}$ to $3 \mathrm{c}$ show respectively the impact of maximum pressure $\left(p_{\max }\right)$, pressure fluctuation $\left(p_{\min } / p_{\max }\right)$ and cavern heat transfer rate $(\lambda)$ on efficiency and cost. It is notable that the efficiency increases with $p_{\max }$ for all A-CAES types (liquid, solid and hybrid), which is due to the fact that exergetic losses are dominated by the compression and expansion processes. In the case of polytropic compression the specific entropy increase per stage may be written $\Delta s_{c}=(1 / \eta-1) R \ln \beta_{c}$, whereas the specifc work input per stage, $w_{c}$, is given by Eq. (7). The ratio $\left(T_{0} \Delta s_{c} / w_{c}\right)$ is a decreasing function of pressure ratio. A similar result holds for expansion, thus leading to the observed trend of $\chi$ with $p_{\max }$. Figure $3 \mathrm{a}$ also shows that the unit storage cost of solid A-CAES increases rapidly with maximum pressure, whereas that of the liquid system decreases slightly. This is due to the dominant impact of pressure vessel costs for the second stage solid TES thermal reservoir. For liquid systems, costs are influenced strongly by the air mass flowrate (via Eq. 17) which decreases with $p_{\max }$ for a given power rating. The hybrid A-CAES shows a tradeoff between these opposing trends but has the lowest cost of all systems.

Increasing the ratio of the minimum to maximum pressure in the cavern improves the efficiency slightly, but significantly increases the cost (Fig. 3b). The increase in $\chi$ stems mainly from reduced cavern thermal losses (see below), whereas the higher unit cost is a consequence of reduced storage density since the cavern is only partially emptied with each cycle.

The dimensionless heat transfer coefficient $\lambda$ is not really a design parameter (except possibly in the case of artificial air receivers) but rather a function of the cavern size, geometry and surrounding rock type. Increasing values of $\lambda$ make the cavern more isothermal, allowing more air to be stored per unit volume and thereby decreasing the unit storage cost, as shown in Fig. 3c. Thermal exergetic losses occur within the cavern due to mixing of inlet air with cavern air (which is generally at a different temperature) and due to heat leakage to and from the surroundings at temperatures different to $T_{0}$. Mixing losses tend to dominate for adiabatic caverns $(\lambda=0)$ whereas the sum of these two loss components tends to peak for the mid-range values of $\lambda$ which, estimates suggest, are likely to be representative of real caverns [32]. The impact on efficiency is, however, relatively small. 


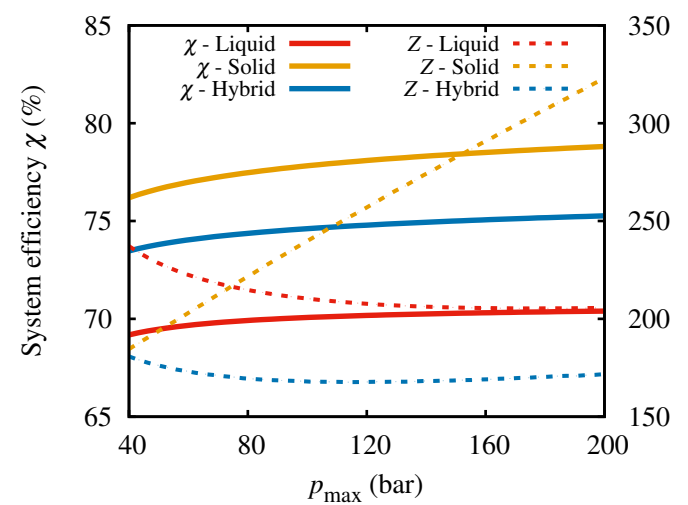

(a) Maximum cavern pressure

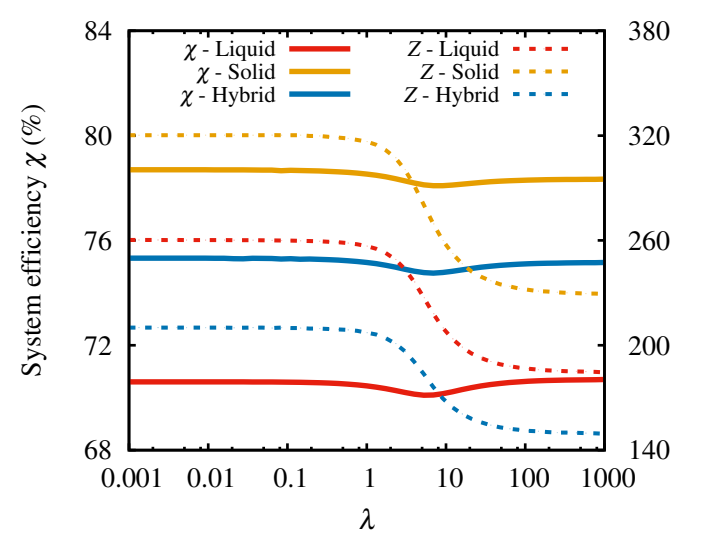

(c) Cavern dimensionless heat transfer rate

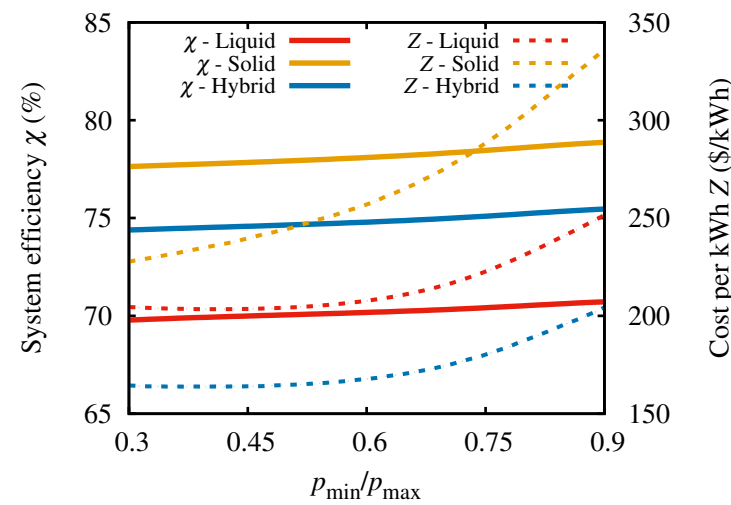

(b) Cavern pressure variation

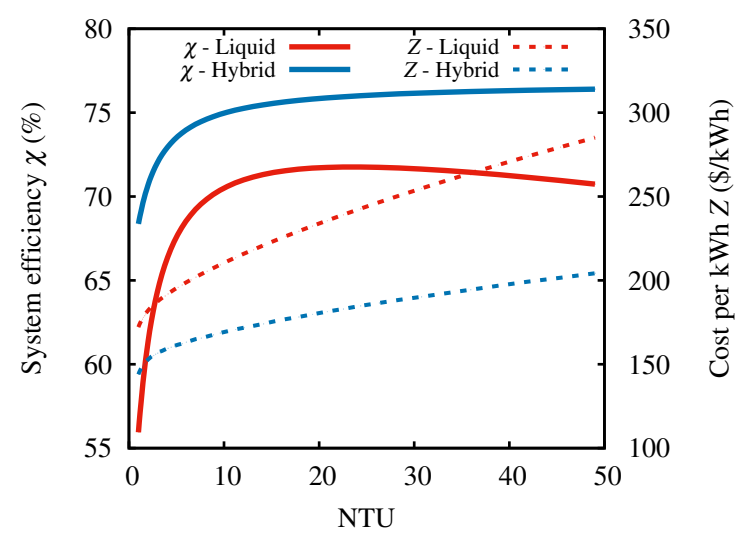

(d) Heat exchanger NTU rating

Figure 3: Variation of efficiency and unit cost with cavern and heat exchanger parameters.

\subsection{Effect of heat exchanger size for liquid and hybrid systems}

The effects of varying the NTU rating of the main heat exchangers is shown in Fig. 3d. Increasing NTU improves heat exchanger effectiveness but with diminishing returns, as shown by Eq. (9). Consequently, the round-trip efficiency increases with NTU for the hybrid system, but the improvement is marginal beyond NTU 10, whereas the cost rises in accord with Eq. (18). For liquid systems, more of the heat exchange occurs at low air pressure where the density is lower and pressure losses are more significant (Eq. 10). These losses outweigh the small improvement in $\varepsilon$ at high NTU such that the efficiency reaches a maximum at NTU $\sim 20$. Since all heat transfer to the storage media occurs via the heat exchangers for liquid systems, the cost increases more rapidly than for hybrid A-CAES.

\subsection{Effect of compression and expansion efficiency}

Increasing the polytropic efficiency of compressors and expanders results in a more or less linear increase in overall efficiency, with $\chi$ increasing by roughly 1.5 percentage points for each percentage point increase in turbomachinery efficiency, as shown in Fig. 4a. The designer has the choice between cheap, low-efficiency compressors and expanders, or expensive high-efficiency ones. The rise in cost is dramatic for turbomachinery efficiencies greater than about $86 \%$, but the shape of these curves is of course dependent on the form of Eq. (17) which, as already noted, is subject to some uncertainty.

\subsection{Effect of packed bed parameters for solid and hybrid systems}

The effects of packed bed utilisation factor $\Pi$, particle size $d_{p}$ and aspect ratio $L / D$ on round-trip efficiency and unit cost are shown in Figs. $4 \mathrm{~b}$ to $4 \mathrm{~d}$. Recall that $\Pi$ is the ratio between the actual and nominal charge times for the solid thermal reservoir, so as $\Pi$ increases more of the reservoir's capacity is exploited. The system cost therefore falls as $\Pi$ rises, but beyond $\Pi \sim 1$ the reservoir is fully charged with each cycle and any attempt to 


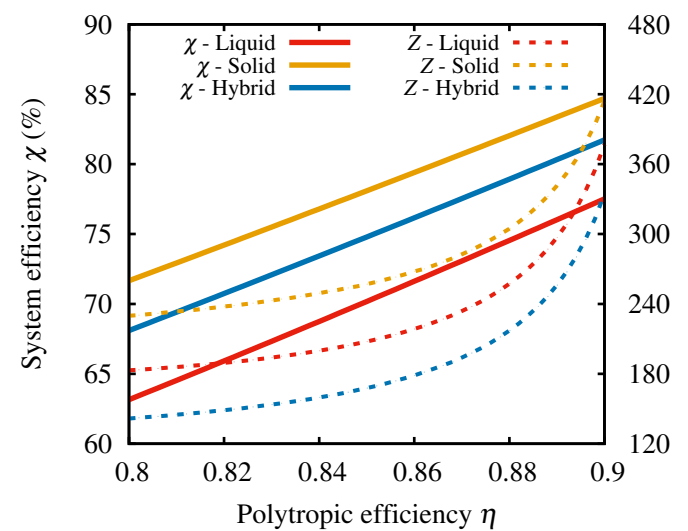

(a) Compression and expansion efficiency

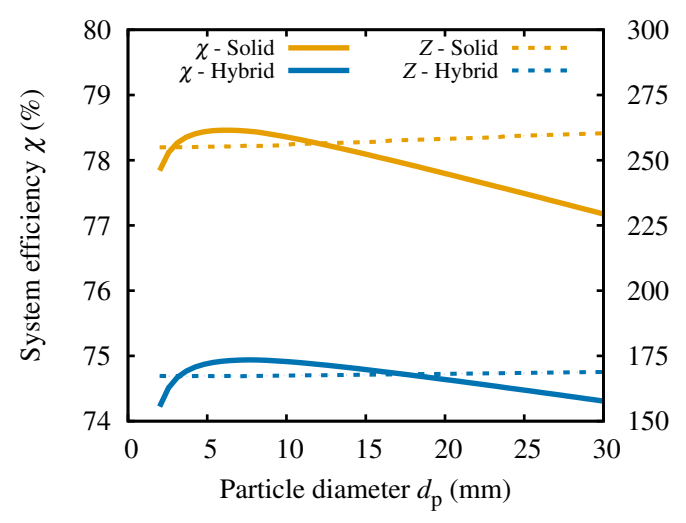

(c) Effective particle diameter

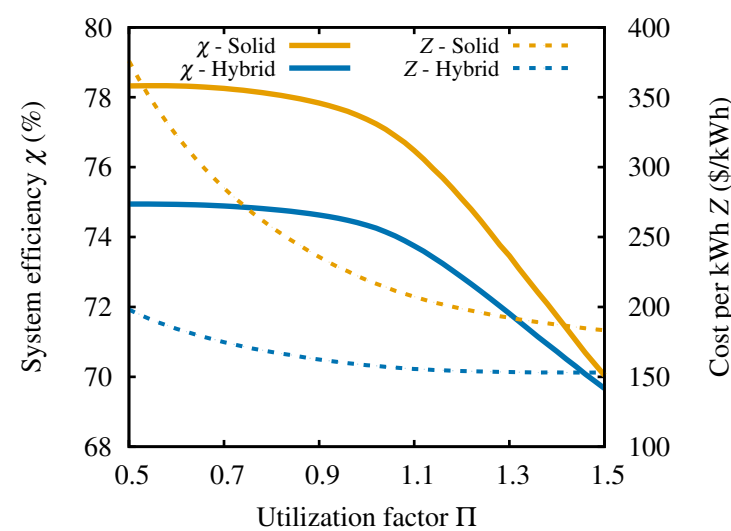

(b) Thermal reservoir utilization

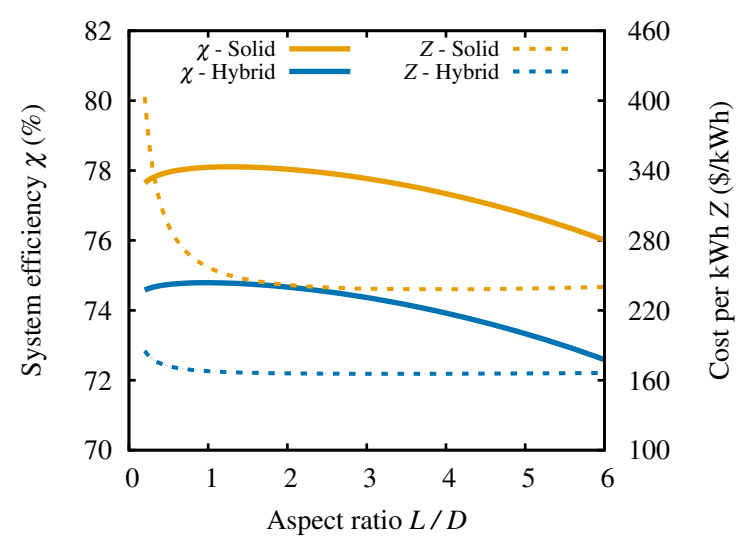

(d) Reservoir aspect ratio

Figure 4: Variation of system efficiency with turbomachinery efficiency and packed bed parameters.

charge it further simply results in hot air issuing from the exit and hence a decrease in efficiency. As discussed in Ref. [19], greater utilisation also leads to steeper temperature gradients in the packed bed and consequently higher losses due to irreversible heat exchange between the air and storage media. The cost may continue to fall beyond $\Pi=1$ because this implies a smaller thermal reservoir, but eventually the impact of increased losses on the returned work, $W_{\mathrm{dis}}$, begins to dominate such that the curve flattens out.

The effective particle diameter $d_{p}$ determines the balance between thermal and pressure losses within the packed bed: small particles provide more surface area thereby decreasing heat transfer losses, but at the expense of a larger pressure drop. There is thus an optimum particle size at which the efficiency is maximum (see Fig. 4c). This optimum will depend on the air mass flow per unit area $G$ and hence on the reservoir aspect ratio. The cost of the packing material and the volume it occupies is assumed independent of $d_{p}$ and therefore the improvement in $\chi$ obtained with smaller particles results in a slight decrease in unit cost $Z$. This is one of the few areas where there is no conflict between cost and efficiency.

In conjunction with the particle size, the aspect ratio $L / D$ also affects the balance between thermal and pressure losses, with long thin reservoirs having efficient heat transfer but larger pressure drop. Again there is an optimum, as shown in Fig. 4d, which will in turn depend on $d_{p}$. This time there is, however, a rapid increase in cost at low values of $L / D$ which is due to "end effects" - i.e., the high surface-to-volume ratio, requiring more insulation and therefore a larger vessel, and the wasted space in the domed end caps of the pressure vessel (which reflect the cost of flanges and high-tensile bolts).

\section{Optimization study}

The above parametric study suggests that hybrid A-CAES has the lowest unit cost whilst the solid system has the highest efficiency. However, strictly this is only the case for the points associated with the nominal design. To find out the best designs across the full design space and provide a thorough comparison between the liquid, solid 


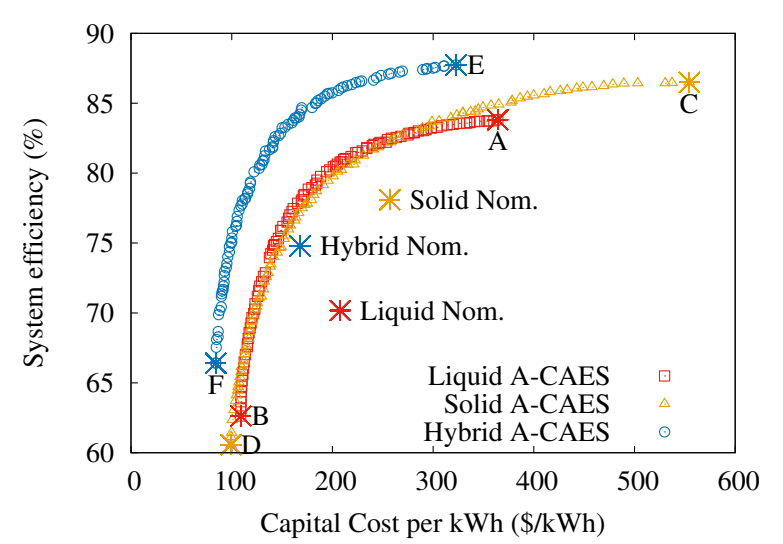

(a) Pareto fronts

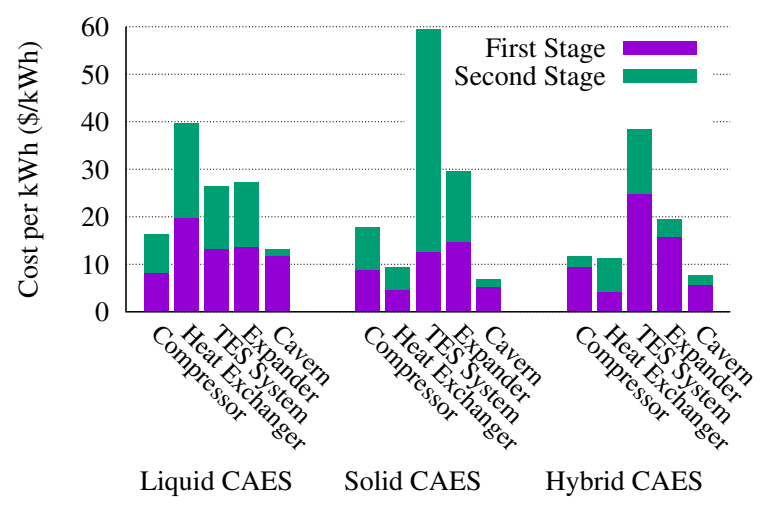

(c) Cost distributions

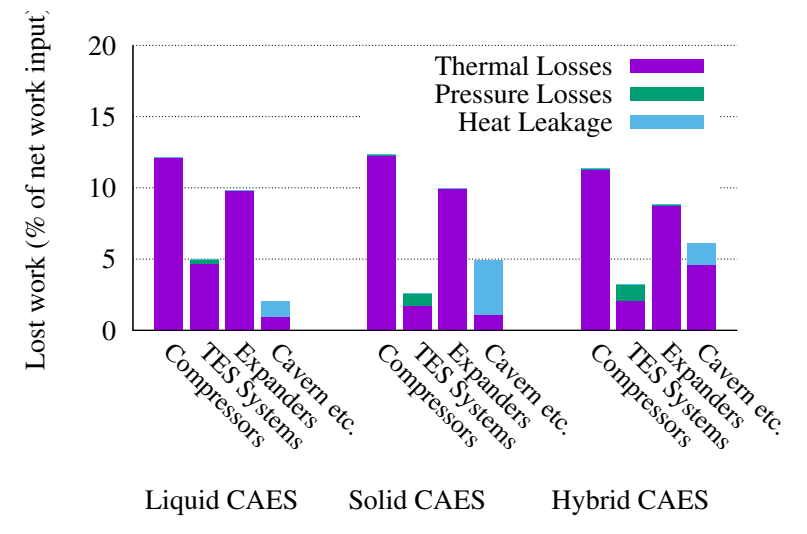

(b) Loss distributions

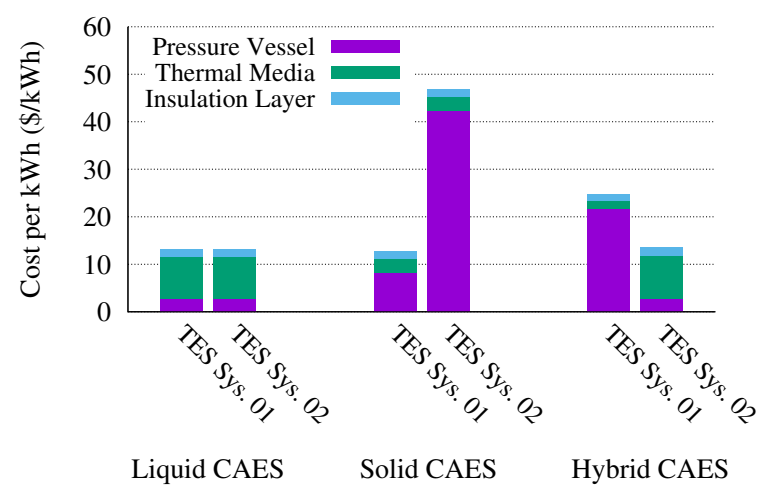

(d) TES Cost distributions

Figure 5: Pareto fronts and loss and cost distributions for the three systems. (Loss and cost distributions are for designs with thermodynamic round-trip efficiency $\chi=70 \%$.)

and hybrid systems, a multi-objective optimisation has been carried out for each A-CAES system. A stochastic optimisation algorithm called NSGA-II, as described in Ref. [33], has been used for this task. The objectives are to maximize the efficiency $\chi$ and minimise the unit $\operatorname{cost} Z$. Boundaries are placed on the design variables to aid the search for the optimum solutions, as summarised in Table 2. In addition, the maximum allowable temperatures of the TES materials are also used as constraints, these being $340^{\circ} \mathrm{C}$ for mineral oil and $600^{\circ} \mathrm{C}$ for magnetite. The best designs emerging from the optimisation are shown in Fig. 5a, where the nominal design points of the three systems are also shown for comparison.

\subsection{Cost and efficiency trade offs and general design trends}

Figure 5a shows so-called Pareto fronts for the three types of A-CAES. These constitute the "leading edge" solutions, with all other designs lying either below or to the right (as in the case of the nominal designs). The Pareto fronts clearly demonstrate the trade offs between cost and efficiency stemming from the various factors discussed in the previous section. Based on the underlying assumptions in the model, it is clear from Fig. 5a that the solid and liquid systems demonstrate similar performance but the hybrid system is superior in that it is either cheaper for the same efficiency, or more efficient for the same cost. It is also notable that there are diminishing returns in trying to further increase $\chi$ when $Z$ is very high, or to further reduce $Z$ when $\chi$ is very low. The trade off is thus most significant at the "knee" of the curves where $\chi$ and $Z$ have moderate values (e.g. $Z=100-200 \$ / \mathrm{kWh}$ or $\chi=75-85 \%$ for the hybrid system).

Table 3 summarises the design variables and resulting performance for the nominal cases and for the six points labelled A through F in Fig. 5a, each of these being at either the highest efficiency or the lowest cost for the three systems. All of these solutions (and in fact all designs on the Pareto fronts) converge to having just two stages in order to reduce costs. On the other hand, there is significant spread in many of the other variables. As would be expected, high values of $\eta_{c / e}$ and NTU correlate with efficient but expensive designs, but different preferences are 
Table 3: Design variables and main results for the nominal and optimal designs indicated in Fig. 5a

\begin{tabular}{cccccccccc}
\hline & \multicolumn{3}{c}{ Liquid A-CAES } & \multicolumn{3}{c}{ Solid A-CAES } & \multicolumn{3}{c}{ Hybrid A-CAES } \\
\cline { 2 - 9 } & Nom. & A & B & Nom. & C & D & Nom. & E & F \\
\hline$N_{\text {stg }}$ & 4 & 2 & 2 & 2 & 2 & 2 & 3 & 2 & 2 \\
$p_{\max }($ bar $)$ & 120 & 100 & 79 & 120 & 195 & 40 & 120 & 40 & 42 \\
$p_{\min } / p_{\max }$ & 0.60 & 0.89 & 0.44 & 0.60 & 0.87 & 0.30 & 0.60 & 0.86 & 0.54 \\
NTU & 9 & 49 & 7 & - & - & - & 9 & 48 & 2 \\
$\eta_{\mathrm{c} / \mathrm{e}}$ & 0.85 & 0.90 & 0.80 & 0.85 & 0.90 & 0.80 & 0.85 & 0.90 & 0.80 \\
$p_{\mathrm{m}}$ & - & - & - & - & - & - & 10 & 30 & 20 \\
$\Pi$ & - & - & - & 1.0 & 1.0 & 1.5 & 1.0 & 1.0 & 1.3 \\
$d_{p}(\mathrm{~mm})$ & - & - & - & 15 & 2.6 & 22.6 & 15 & 2.1 & 5.0 \\
$L / D$ & - & - & - & 1.0 & 0.4 & 2.6 & 1.0 & 0.4 & 3.1 \\
\hline$\chi(\%)$ & 70.2 & 83.8 & 62.6 & 78.1 & 86.5 & 60.6 & 74.8 & 87.7 & 66.4 \\
$Z(\$ / \mathrm{kWh})$ & 208 & 364 & 109 & 257 & 554 & 99 & 168 & 323 & 84 \\
\hline
\end{tabular}

Table 4: Main results for $70 \%$ efficiency cases

\begin{tabular}{llll}
\hline & Liquid CAES & Solid CAES & Hybrid CAES \\
\hline System Efficiency & $70.3 \%$ & $70.2 \%$ & $70.2 \%$ \\
Cost per kWh & $123 \$ / \mathrm{kWh}$ & $123 \$ / \mathrm{kWh}$ & $88 \$ / \mathrm{kWh}$ \\
Capital Cost & $37 \mathrm{M} \$$ & $39 \mathrm{M} \$$ & $26 \mathrm{M} \$$ \\
Net Output Work & $303 \mathrm{MWh}$ & $320 \mathrm{MWh}$ & $298 \mathrm{MWh}$ \\
Net Input Work & $431 \mathrm{MWh}$ & $456 \mathrm{MWh}$ & $425 \mathrm{MWh}$ \\
\hline
\end{tabular}

exhibited by the three systems for other parameters. For example, liquid systems tend to select the highest value of $p_{\max }$ consistent with the limit on liquid storage temperature, whereas the hybrid systems opt for the lowest cavern pressure and solid systems show a strong cost-efficiency trade off, as discussed in section 5.1.

\subsection{Comparison of designs with fixed efficiency}

The main results for optimised designs at a fixed round-trip efficiency of $70 \%$ are shown in Table 4. (Recall that mechanical and electrical losses have not been included, so the whole-system efficiency will be somewhat lower.) For this level of efficiency the capital cost per kWh for the hybrid system is some 15 to $25 \%$ below that of the other two A-CAES types, and the margin is even greater at higher efficiencies. It is of interest to see how this has been achieved, and how the losses and costs are distributed amongst the different components. This information is provided in the histograms of Figs. $5 \mathrm{~b}$ to $5 \mathrm{~d}$.

For all three systems, losses are dominated by irreversibility in the compressors and expanders. Compression losses are slightly greater than expansion losses because it has been assumed that these processes have the same polytropic efficiency $\left(\eta_{c}=\eta_{e}=\eta\right.$ ), which gives (for a given pressure ratio) $\Delta s_{c} / \Delta s_{e}=1 / \eta$. It is possible that slightly better designs might be realised if this assumption were relaxed. The next biggest loss for liquid systems is associated with the TES and is due mainly to irreversible heat exchange. This loss is much smaller for solid TES because of the direct nature of heat exchange and the possibility of using small particles with very large heattransfer area. At additional cost, losses in liquid TES systems might be reduced further by the use of compact heat exchangers that have channel sizes smaller than the $3 \mathrm{~mm}$ assumed here. Finally, the loss category labelled 'cavern etc.' includes direct cavern losses (as described in section 5.1) plus exergetic losses due to heat rejection from the auxiliary heat exchangers the exit loss due to air being returned to atmosphere after discharge at a temperature above $T_{0}$. This category of loss is larger for solid systems, particularly when the packed bed is undersized relative to the cavern becuase significant quantities of heat must then be rejected via the auxiliary heat exchangers.

Figure 5c, shows that the solid A-CAES system is the most expensive. As previously noted, this is due to the very high cost of the second-stage thermal reservoir. Meanwhile, the cost of the first-stage thermal store is lower than that of the liquid system and has a higher allowable top temperature. These are the main factors that provide the motivation for the hybrid system. Note that the turbomachinery (and other) costs are unequally distributed between the first and second stages for the hybrid system because the pressure ratios are different, in accord with the different maximum temperatures for solid and liquid TES. (Note that first and second stage refer to well and 


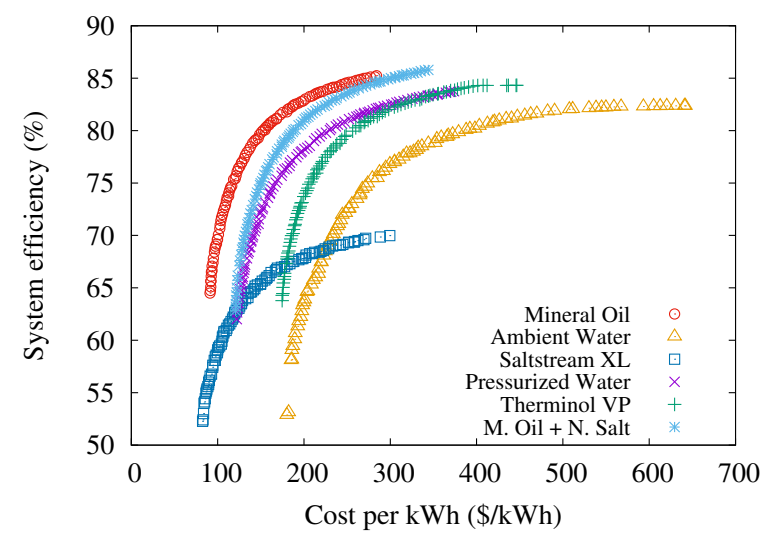

Figure 6: Pareto fronts for liquid A-CAES with different thermal fluids

Table 5: Cost and thermodynamic properties of commonly used TES liquids [14, 15, 34-36]

\begin{tabular}{ccccc}
\hline & $C(\$ / \mathrm{t})$ & $\rho\left(\mathrm{kg} / \mathrm{m}^{3}\right)$ & $c_{p}(\mathrm{~J} / \mathrm{kg} \cdot \mathrm{K})$ & Temperature $\left({ }^{\circ} \mathrm{C}\right)$ \\
\hline Water & 1.0 & 1000 & 4174 & $0 \sim 100$ \\
P. Water (20 bar) & 1.0 & 960 & 4210 & $0 \sim 213$ \\
Mineral Oil & 2642 & 770 & 2600 & $\sim 340$ \\
Therminol VP & 5000 & 1050 & 1600 & $12 \sim 257$ \\
Solar Salt & 1000 & 1850 & 1550 & $230 \sim 450$ \\
Saltstream XL & 1000 & 1870 & 1450 & $120 \sim 500$ \\
\hline
\end{tabular}

mining costs respectively in the case of the cavern costs.) The distribution of costs between different components of the TES systems is shown in Fig. 5d from which it is clear that containment vessel costs dominate for solid systems (due to pressurisation) whilst the mineral oil is the most expensive part of liquid TES.

\subsection{Choice of stotage media for liquid TES}

Figure 6 compares Pareto fronts for liquid systems obtained with different storage media. The cost and main thermodynamic properties of these liquids are summarised in Table 5. From the figure it is clear that mineral oil is the best candidate with other fluids being inferior for a variety of reasons. For example, ambient water has a low boiling point and therefore requires too many stages to achieve a reasonable cavern pressure. The temperature range can be extended by pressurising the storage vessel, but this quickly becomes very expensive. Therminol VP is more expensive than mineral oil despoite its boiling point and heat capacity being lower. Saltstream XL (nitrate salt) has the highest boiling point and heat capacity, whilst the lowest cost. However, it solidifies at room temperature (the temperature at which the compressed air is stored) and air exiting from the main heat exchanger must therefore be hotter than the melting point $\left(120^{\circ} \mathrm{C}\right)$. This requires subsequent heat rejection to the environment, leading to significant exergetic loss and a reduction in round-trip efficiency. It may be possible to get round this problem by "recuperation" (i.e., using an additional heat exchanger to preheat atmospheric inlet air during charge and cool the exhaust air during discharge) but this possibility has not been explored here. Other nitrate salts have similar problems but with even higher melting points. In principle, it would be possible to extend the temperature range by operating these salts in series with a second thermal fluid, but this roughly doubles the TES costs. Mineral oil alone therefore emerges as the most economical option.

\subsection{Sensitivity to cost assumptions}

The impact of using optimistic, nominal and pessimistic cost factors (see Table 1) on the Pareto fronts for the hybrid system is shown in Fig. 7a. Unsurprisingly, these factors have no impact on the system efficiency $\chi$, and the three curves are simply shifted relative to one another along the cost axis. This serves to show that unit costs (i.e., per kWh storage capacity) might be expected to fall within the range of 70 to $100 \$ / \mathrm{kWh}$ (ex. motor / generator, control and electrical connection costs) for a $70 \%$ efficient hybrid system with a nominal rating of $100 \mathrm{MW}$ and four hours capacity. 


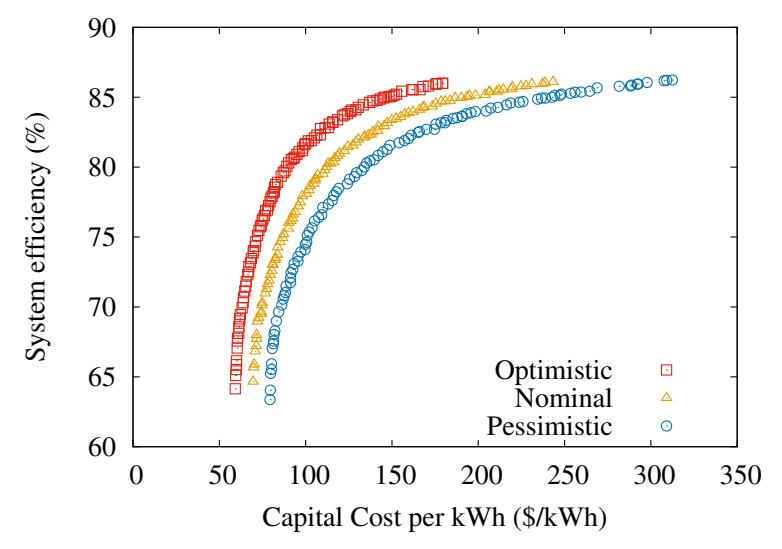

(a) Impact of the cost equation constants

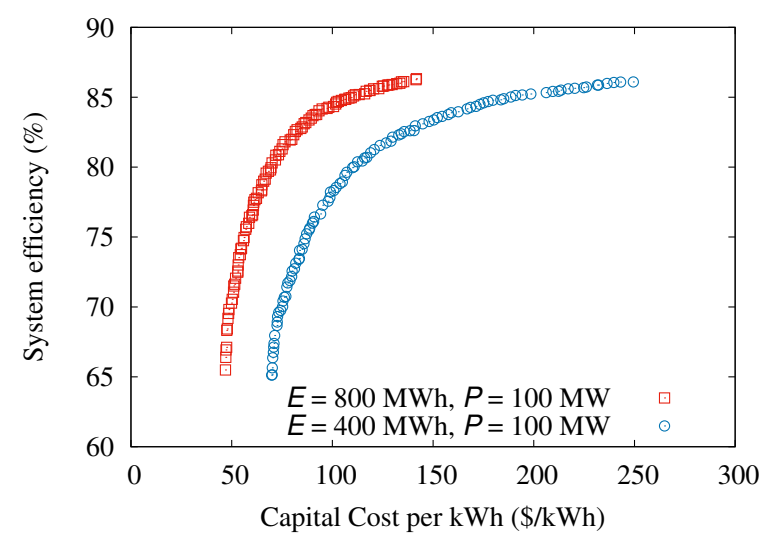

(b) Impact of the storage capacity $E$

Figure 7: Pareto fronts of the hybrid A-CAES systems: (a) with different cost factor scenarios (nominal, optimistic and pessimistic cases); (b) with different storage capacities (using nominal cost factors).

\subsection{Effect of the stored energy-to-power ratio}

The capital cost of some components (compressors, expanders and heat exchangers) is roughly proportional to the rated power, whereas that of others (the cavern and TES systems) depends mainly on the stored energy. An approximation to the total system cost is therefore given by

$$
Z_{\mathrm{tot}} \simeq C_{\mathrm{P}} P+C_{\mathrm{E}} W_{\mathrm{dis}}
$$

where $P$ and $W_{\text {dis }}$ are the power and discharged work, and $C_{\mathrm{P}}$ and $C_{\mathrm{E}}$ are corresponding cost factors in $\$ / \mathrm{kW}$ and $\$ / \mathrm{kWh}$ respectively. The overall unit cost $Z$, as previously defined, is thus

$$
Z \simeq C_{\mathrm{P}} / \tau_{\mathrm{dis}}+C_{\mathrm{E}}
$$

where $\tau_{\mathrm{dis}}=W_{\mathrm{dis}} / P$ is the discharge duration, which reflects the storage capacity and has been set at four hours for the systems considered so far. Equations (20) and (21) are not quite exact: for example, the cost per kWh of the TES is influenced slightly by its size via the level of insulation required.

Figure $7 \mathrm{~b}$ shows Pareto fronts for two hybrid systems, both rated at $100 \mathrm{MW}$ but one with four and the other with eight hours of storage. It is evident from Eq. (21) that the unit $\operatorname{cost} Z$ will be lower for the larger system. On the basis of Fig. 7b, estimates of $C_{\mathrm{P}}$ and $C_{\mathrm{E}}$ for a hybrid system with $\chi=70 \%$ are $\sim 250 \$ / \mathrm{kW}$ and $\sim 20 \$ / \mathrm{kWh}$ respectively. (Recall however that some costs have not been included, as described in section 4.)

\section{Conclusions}

Thermodynamic and capital cost models have been devised for A-CAES system components, and the appropriate materials selected for solid and liquid thermal stores. A hybrid A-CAES system is proposed that combines lowpressure solid 7TES with liquid TES for the high-pressure compression stages. This has been compared with other systems that use just liquid or just solid TES. A combination of parametric studies and multi-objective optimisation has been used to undertake this comparison, from which the following conclusions may be drawn:

1. There are rapidly diminishing returns at the extremes of low cost and high efficiency (i.e., the Pareto fronts become vertical and horizontal respectively) such that the cost-efficiency trade off is most pronounced in the intermediate range, typically with $\chi$ around $80 \%$.

2. The main factors controlling the cost-efficiency trade off are the polytropic efficiency of compressors and turbines, the NTU of heat exchangers (for liquid and hybrid systems), the reservoir "utilization factor" $\Pi$ and reservoir aspect ratio $L / D$ (for solid and hybrid systems).

3. The hybrid system demonstrates a lower cost than the other two systems for a given efficiency (or higher efficiency for a given cost). Although this conclusion might be affected by different cost assumptions, the margin is reasonably significant - i.e., typically 15 to $25 \%$ lower cost at fixed $\chi$. The main reason for this advantage is that solid TES is cheap when operated at low pressure and does not require indirect heat exchange, whereas at high pressure it is much more expensive than liquid TES. 
4. Mineral oil was found to be the best thermal fluid for liquid TES due to its relatively high allowable temperature and low unit cost.

\section{Nomenclature}

\begin{tabular}{|c|c|c|c|c|}
\hline Symbol & Description & Units & Symbol & Description \\
\hline$A$ & Cavern surface area & $\mathrm{m}^{2}$ & $\beta$ & Pressure ratio per stage \\
\hline$A_{\mathrm{c}}$ & Cavern inlet cross-sectional area & $\mathrm{m}^{2}$ & $\gamma$ & Adiabatic index \\
\hline$c_{f}$ & friction coefficient & & $\delta$ & Infinitesimal process \\
\hline$c_{p}$ & Specific heat at constant pressure & $\mathrm{J} \mathrm{kg}^{-1} \mathrm{~K}^{-1}$ & $\varepsilon$ & Heat exchanger effectiveness \\
\hline$c_{v}$ & Specific heat at constant volume & $\mathrm{J} \mathrm{kg}^{-1} \mathrm{~K}^{-1}$ & $\eta$ & Polytropic efficiency \\
\hline $\mathrm{Cr}$ & Heat capacity ratio & & $\lambda$ & Dimensionless heat transfer coefficient \\
\hline$\dot{C}$ & Heat capacity rate & $\mathrm{W} \mathrm{K}^{-1}$ & $\rho$ & Density \\
\hline$d_{p}$ & Particle diameter & $\mathrm{m}$ & $\tau$ & Time scale \\
\hline$E$ & Energy & $\mathrm{J}$ or MWh & $\varphi$ & Reservoir aspect ratio \\
\hline$f$ & Pressure loss factor & & $\phi$ & Polytropic exponent \\
\hline$G$ & Mass flowrate per unit area & $\mathrm{kg} \mathrm{m}^{-2} \mathrm{~s}^{-1}$ & $\chi$ & Round-trip efficiency \\
\hline$h$ & Specific enthalpy & $\mathrm{J} \mathrm{kg}^{-1}$ & $\Pi$ & Reservoir utilization factor \\
\hline$k$ & Cost coefficient / Isentropic Index & & & \\
\hline$l$ & Length scale & & Subscript & Description \\
\hline$m$ & Mass & $\mathrm{kg}$ & 0 & Ambient conditions \\
\hline$\dot{m}$ & Mass flow rate & $\mathrm{kg} \mathrm{s}^{-1}$ & $\mathrm{a}, \mathrm{w}$ & Air, liquid \\
\hline$n$ & Solid TES number & & $\mathrm{c}, \mathrm{e}$ & Compressor, expander \\
\hline$N$ & Total stage number & & cave & Cavern \\
\hline NTU & Heat transfer unit & & chg, dis & Charge, discharge \\
\hline$p$ & Pressure & $\mathrm{Pa}$ & fil, ins, $P V$ & Filling, insulation and pressure vessel \\
\hline$P$ & Power & MW & $\mathrm{g}, \mathrm{s}$ & Gas, solid \\
\hline$\dot{Q}$ & Heat transfer rate & $\mathrm{W}$ & hot, cold & Hot fluid, cold fluid \\
\hline$\widetilde{R}$ & System pressure ratio & & in, out & Inlet, outlet \\
\hline$R_{g}$ & Specific gas constant & $\mathrm{J} \mathrm{kg}^{-1} \mathrm{~K}^{-1}$ & $\min , \max$ & Minimum, maximum \\
\hline$s^{s}$ & Specific entropy & $\mathrm{J} \mathrm{kg}^{-1} \mathrm{~K}^{-1}$ & opt & Optimal \\
\hline$\dot{s}_{g}$ & Entropy generation rate & $\mathrm{W} \mathrm{K}^{-1}$ & $\mathrm{~m}$ & Intermediate \\
\hline St & Stanton Number & & well, mine & Well drilling, solution mining \\
\hline$S_{v}$ & Particle surface-to-volume ratio & & & \\
\hline$T$ & Temperature & $\mathrm{K}$ & Acronym & Description \\
\hline$U$ & Heat transfer coefficient & $\mathrm{W} \mathrm{m}{ }^{2} \mathrm{~K}^{-1}$ & A-CAES & Adiabatic Compressed Air Energy Storage \\
\hline$w$ & Specific work & $\mathrm{m}^{3} \mathrm{~kg}^{-1}$ & CAES & Compressed Air Energy Storage \\
\hline$Z$ & Total cost/Unit storage cost & $\$ \mathrm{kWh}^{-1}$ & TES & Thermal Energy Storage \\
\hline
\end{tabular}

\section{Acknowledgements}

Haobai Xue gratefully acknowledges Cambridge Trust and China Scholarship Council (CSC) for the studentship which is allowing him to develop this research project at Cambridge University Engineering Department.

\section{References}

[1] The UK renewable energy strategy. Report CM7686, 2009.

[2] Chris Bullough, Christoph Gatzen, Christoph Jakiel, Martin Koller, Andreas Nowi, and Stefan Zunft. Advanced adiabatic compressed air energy storage for the integration of wind energy, 2004.

[3] David MacKay. Sustainable Energy-without the hot air. UIT Cambridge, 2009.

[4] Haisheng Chen, Thang Ngoc Cong, Wei Yang, Chunqing Tan, Yongliang Li, and Yulong Ding. Progress in electrical energy storage system: A critical review. Progress in Natural Science, 19(3):291-312, 2009. 
[5] Marcus Budt, Daniel Wolf, Roland Span, and Jinyue Yan. A review on compressed air energy storage: Basic principles, past milestones and recent developments. Applied Energy, 170:250-268, 2016.

[6] Xing Luo, Jihong Wang, Christopher Krupke, Yue Wang, Yong Sheng, Jian Li, Yujie Xu, Dan Wang, Shihong Miao, and Haisheng Chen. Modelling study, efficiency analysis and optimisation of large-scale adiabatic compressed air energy storage systems with low-temperature thermal storage. Applied Energy, 162:589$600,2016$.

[7] RWE Power. ADELE-adiabatic compressed air energy storage for electricity supply. Report, 2012.

[8] Edward Barbour, Dimitri Mignard, Yulong Ding, and Yongliang Li. Adiabatic compressed air energy storage with packed bed thermal energy storage. Applied Energy, 155:804-815, 2015.

[9] Daniel Wolf and Marcus Budt. LTA-CAES-a low-temperature approach to adiabatic compressed air energy storage. Applied Energy, 125:158-164, 2014.

[10] Giuseppe Grazzini and Adriano Milazzo. Thermodynamic analysis of CAES/TES systems for renewable energy plants. Renewable Energy, 33(9):1998-2006, 2008.

[11] Francesco Buffa, Simon Kemble, Giampaolo Manfrida, and Adriano Milazzo. Exergy and exergoeconomic model of a ground-based CAES plant for peak-load energy production. Energies, 6(2):1050-1067, 2013.

[12] Ramesh K Shah and Dusan P Sekulic. Fundamentals of heat exchanger design. John Wiley \& Sons, 2003.

[13] Alexander White, Joshua McTigue, and Christos Markides. Wave propagation and thermodynamic losses in packed-bed thermal reservoirs for energy storage. Applied Energy, 130:648-657, 2014.

[14] S Ushak, AG Fernández, and M Grageda. Using molten salts and other liquid sensible storage media in thermal energy storage (tes) systems. Advances in Thermal Energy Storage Systems: Methods and Applications, 1st ed.; Cabeza, LF, Ed, pages 49-63, 2014.

[15] W-D Steinmann. Thermal energy storage systems for concentrating solar power (csp) technology. In $A d-$ vances in Thermal Energy Storage Systems, pages 511-531. Elsevier, 2015.

[16] Frank W Schmidt, A John Willmott, et al. Thermal energy storage and regeneration. Hemisphere Publishing Corporation Washington, 1981.

[17] J.A. Willmott. Dynamics of Regenerative Heat Transfer. Taylor \& Francis, 2002.

[18] Alexander J White. Loss analysis of thermal reservoirs for electrical energy storage schemes. Applied Energy, 88(11):4150-4159, 2011.

[19] Alexander J White, Joshua D McTigue, and Christos N Markides. Analysis and optimisation of packedbed thermal reservoirs for electricity storage applications. Proceedings of the Institution of Mechanical Engineers, Part A: Journal of Power and Energy, 230(7):739-754, 2016.

[20] Richard G Holdich. Fundamentals of particle technology. Midland Information Technology and Publishing, 2002.

[21] Juan Carlos Ordóñez and Adrian Bejan. Entropy generation minimization in parallel-plates counterflow heat exchangers. International Journal of Energy Research, 24(10):843-864, 2000.

[22] Robert B Laughlin. Pumped thermal grid storage with heat exchange. Journal of Renewable and Sustainable Energy, 9(4):044103, 2017.

[23] Joshua D McTigue and Alexander J White. Segmented packed beds for improved thermal energy storage performance. IET Renewable Power Generation, 2016.

[24] Antonio Valero, Miguel A Lozano, Luis Serra, George Tsatsaronis, Javier Pisa, Christos Frangopoulos, and Michael R von Spakovsky. CGAM problem: definition and conventional solution. Energy, 19(3):279-286, 1994.

[25] Robert B. Schainker and Abhi Rao. Compressed air energy storage (CAES) scoping for california, usa. Report CEC-500-2008-069, California Energy Commission, 2008. 
[26] AF Massardo and M Scialò. Thermoeconomic analysis of gas turbine based cycles. Journal of engineering for gas turbines and power, 122(4):664-671, 2000.

[27] Leandro Galanti and Aristide F Massardo. Thermoeconomic analysis of micro gas turbine design in the range 25-500 kwe. In Proceedings of ASME turbo expo, pages 14-18, 2010.

[28] Alberto Traverso, Aristide F Massardo, Walter Cazzola, and Giovanni Lagorio. Widget-temp: a novel webbased approach for thermoeconomic analysis and optimization of conventional and innovative cycles. In ASME Turbo Expo 2004: Power for Land, Sea, and Air, pages 623-631. American Society of Mechanical Engineers, 2004.

[29] R Williams. Six-tenths factor aids in approximating costs. Chemical Engineering, 54(12):124-125, 1947.

[30] Pierre Berest, Benoît Brouard, and JG Durup. Tightness tests in salt-cavern wells. Oil \& Gas Science and Technology, 56(5):451-469, 2001.

[31] JL Silveira and CE Tuna. Thermoeconomic analysis method for optimization of combined heat and power systems. part i. Progress in energy and Combustion Science, 29(6):479-485, 2003.

[32] Alexander J. White. An exergetic analysis of cavern-related phenomena for CAES, 12-14 July 2017. Presentation at the Offshore Energy Storage Conference 2017.

[33] Kalyanmoy Deb, Amrit Pratap, Sameer Agarwal, and TAMT Meyarivan. A fast and elitist multiobjective genetic algorithm: NSGA-II. IEEE transactions on evolutionary computation, 6(2):182-197, 2002.

[34] James Macnaghten. Commercial potential of different large scale thermal storage technologies under development globally, 8 June 2016. UK Energy Storage Conference 2016.

[35] Michael E Van Valkenburg, Robert L Vaughn, Margaret Williams, and John S Wilkes. Thermochemistry of ionic liquid heat-transfer fluids. Thermochimica Acta, 425(1):181-188, 2005.

[36] Thomas Bauer, Nicole Pfleger, Nils Breidenbach, Markus Eck, Doerte Laing, and Stefanie Kaesche. Material aspects of solar salt for sensible heat storage. Applied energy, 111:1114-1119, 2013. 